Supporting Information for

\title{
Understanding the Reductive Decomposition of Highly Concentrated Li Salt/Sulfolane Electrolytes during Li Deposition and Dissolution
}

Yosuke Ugata, ${ }^{\dagger}$ Ryoichi Tatara,${ }^{\dagger}$ Toshihiko Mandai, ${ }^{\ddagger}$ Kazuhide Ueno, ${ }^{\dagger}{ }^{\S}$ Masayoshi Watanabe,,${ }^{\S} *$ and Kaoru Dokko ${ }^{\dagger},, *$

'Department of Chemistry and Life Science, Yokohama National University, 79-5 Tokiwadai, Hodogayaku, Yokohama 240-8501, Japan

${ }^{\ddagger}$ Center for Green Research on Energy and Environmental Materials, National Institute for Materials Science, 1-1 Namiki, Tsukuba, Ibaraki 305-0044, Japan

${ }^{\S}$ Advanced Chemical Energy Research Center, Institute of Advanced Sciences, Yokohama National University, 79-5 Tokiwadai, Hodogaya-ku, Yokohama 240-8501, Japan

*CORRESPONDING AUTHOR

E-mail: mwatanab@ynu.ac.jp (M.W.)

E-mail: dokko-kaoru-js@ynu.ac.jp (K.D.) 
Table S1. Viscosity $(\eta)$, concentration of Li salt $(c)$, and ionic conductivity $(\sigma)$ of the $[$ LiTFSA $] /[\mathrm{SL}]=$ $1 / 2$ and $[\mathrm{LiFSA}] /[\mathrm{SL}]=1 / 3$ electrolytes at $30^{\circ} \mathrm{C}$. The values of $\eta, c$, and $\sigma$ of the $[\mathrm{LiTFSA}] /[\mathrm{SL}]=1 / 2$ and $[\mathrm{LiFSA}] /[\mathrm{SL}]=1 / 3$ electrolytes were obtained from ref. 14 and 13, respectively.

\begin{tabular}{cccc}
\hline Electrolyte & $\begin{array}{c}\eta \\
\mathrm{mPa} \mathrm{s}\end{array}$ & $/ \mathrm{mol} \mathrm{dm}^{-3}$ & $\begin{array}{c}\sigma \\
/ \mathrm{mS} \mathrm{cm}^{-1}\end{array}$ \\
\hline$[\mathrm{LiTFSA}] /[\mathrm{SL}]=1 / 2$ & 627 & 2.97 & 0.42 \\
{$[\mathrm{LiFSA}] /[\mathrm{SL}]=1 / 3$} & 121 & 2.66 & 2.19 \\
\hline
\end{tabular}

\section{ECMS Cell}

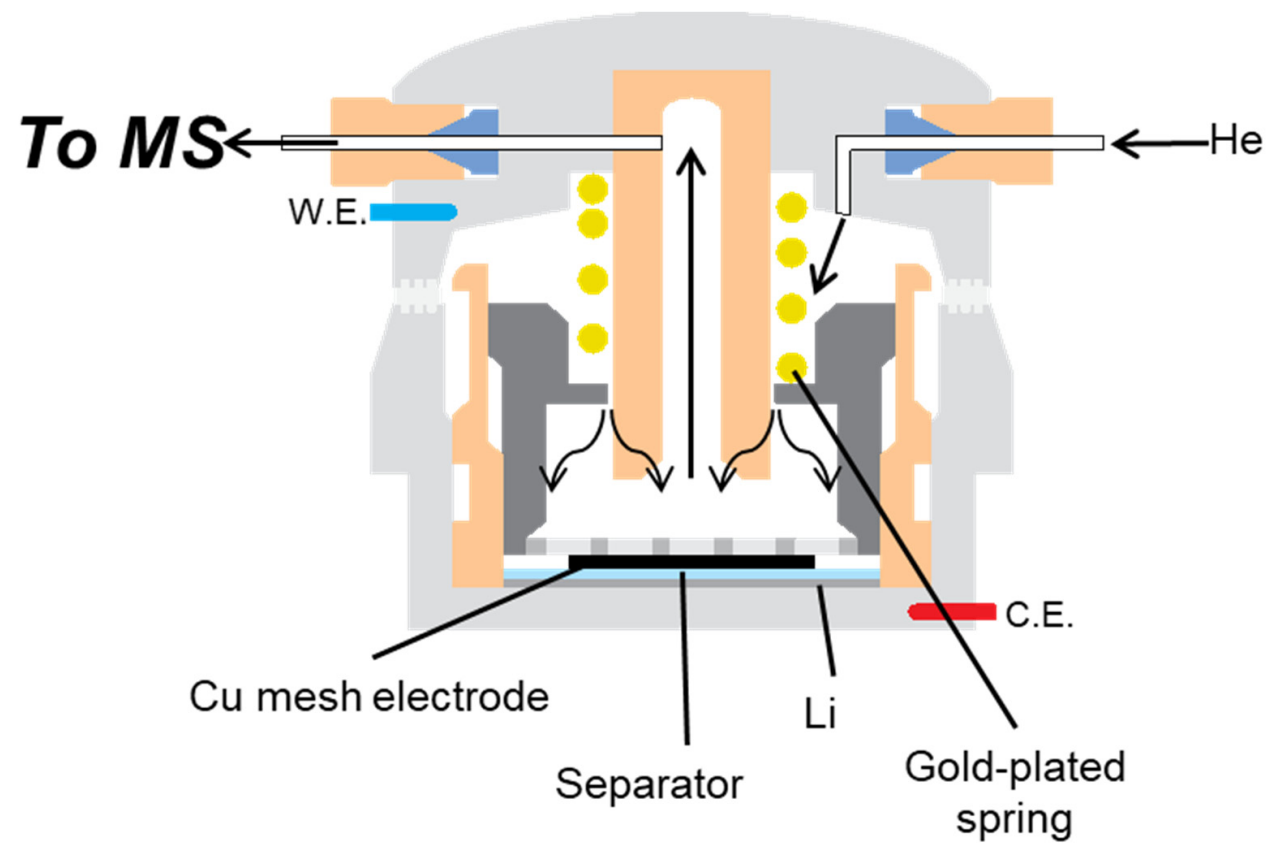

Figure S1. Schematic representation of the cell used for on-line electrochemical mass spectrometry. 


\section{Gas Chromatography-Mass Spectrometry}

Gas chromatography-mass spectrometry analysis was performed using Agilent 5977A GC/MS (Agilent), with a medium polarity column (DB-200, Agilent). Before the GCMS measurement, the Li metal was electrochemically deposited on the $\mathrm{Cu}$ electrode in a $[\mathrm{Li}|[\mathrm{LiTFSA}] /[\mathrm{SL}]=1 / 2| \mathrm{Cu}]$ coin-type cell at a current density of $0.1 \mathrm{~mA} \mathrm{~cm}^{-2}$ for $10 \mathrm{~h}$. The sample electrolyte was extracted by centrifugation of the separator removed from the $\mathrm{Li} / \mathrm{Cu}$ cell after Li deposition; the electrolyte was diluted five times by volume with acetonitrile. The control electrolyte $([\mathrm{LiTFSA}] /[\mathrm{SL}]=1 / 2)$ and the electrolyte after Li deposition were injected into the GC column. The peak observed for the latter electrolyte at a retention time of $5.27 \mathrm{~min}$ (Figure S2a) can be assigned to THT, based on the mass spectrum (Figure S2b).
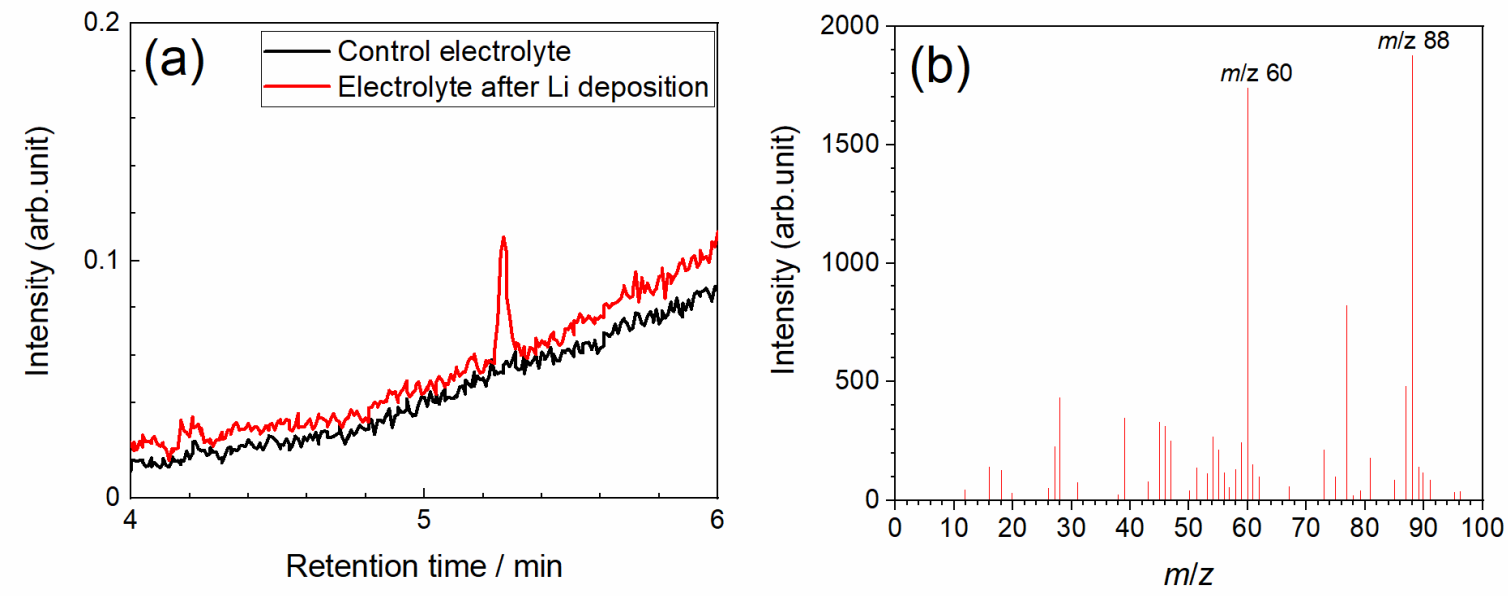

Figure S2. (a) GCMS chromatograms of the control electrolyte ([LiTFSA]/[SL] $=1 / 2$ ) and the electrolyte after Li deposition. (b) Mass spectrum of the component eluted at a retention time of $5.27 \mathrm{~min}$. 


\section{Electrochemical Mass Spectrometry}
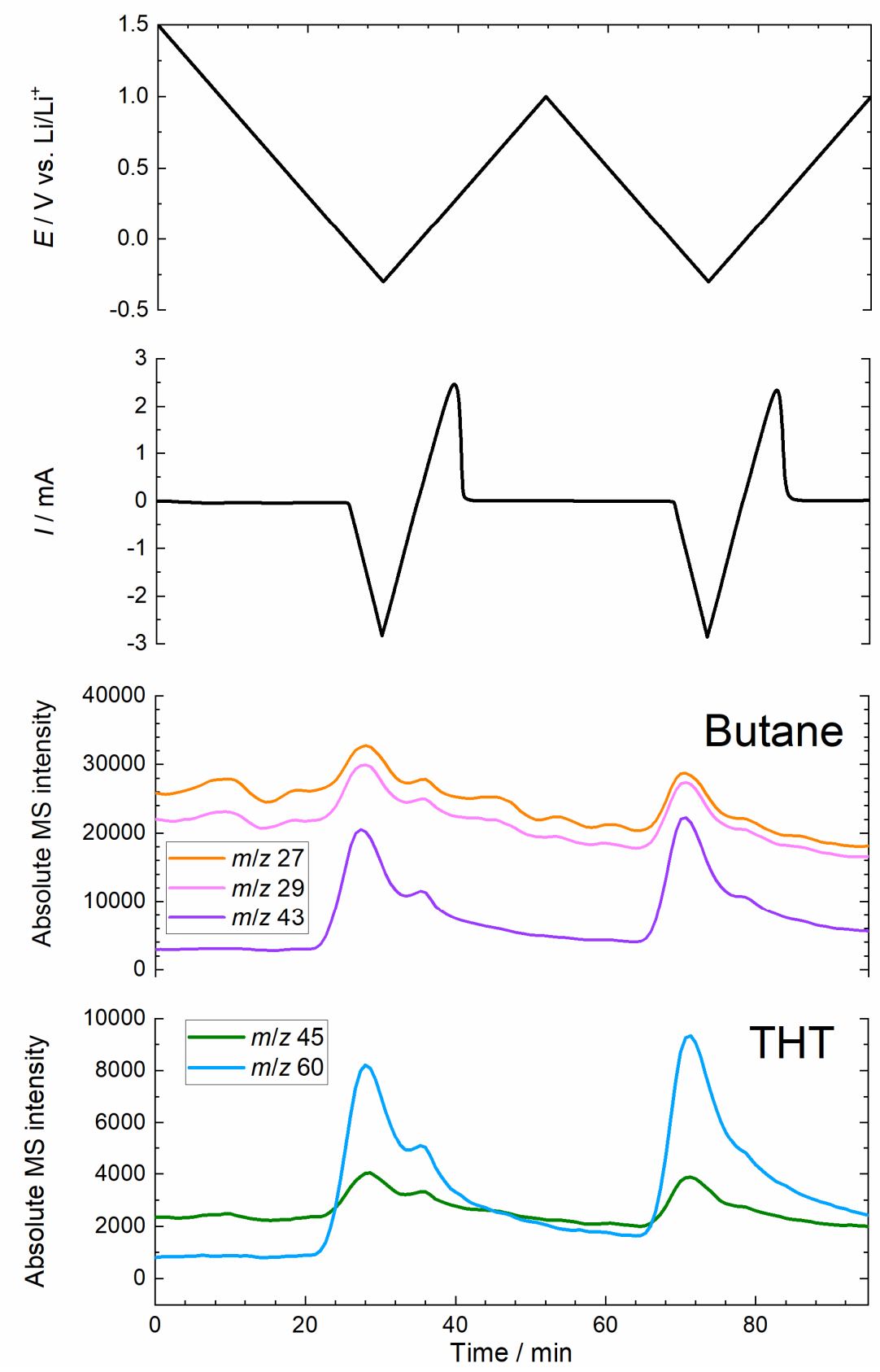

Figure S3. MS intensities of the fragment ion peaks of butane and tetrahydrothiophene (THT) observed for the $\mathrm{Li} / \mathrm{Cu}$ cell with the $[\mathrm{LiTFSA}] /[\mathrm{SL}]=1 / 2$ electrolyte during the initial two $\mathrm{CV}$ cycles at a scan rate of $1 \mathrm{mV} \mathrm{s}^{-1}$ at $30^{\circ} \mathrm{C}$. 

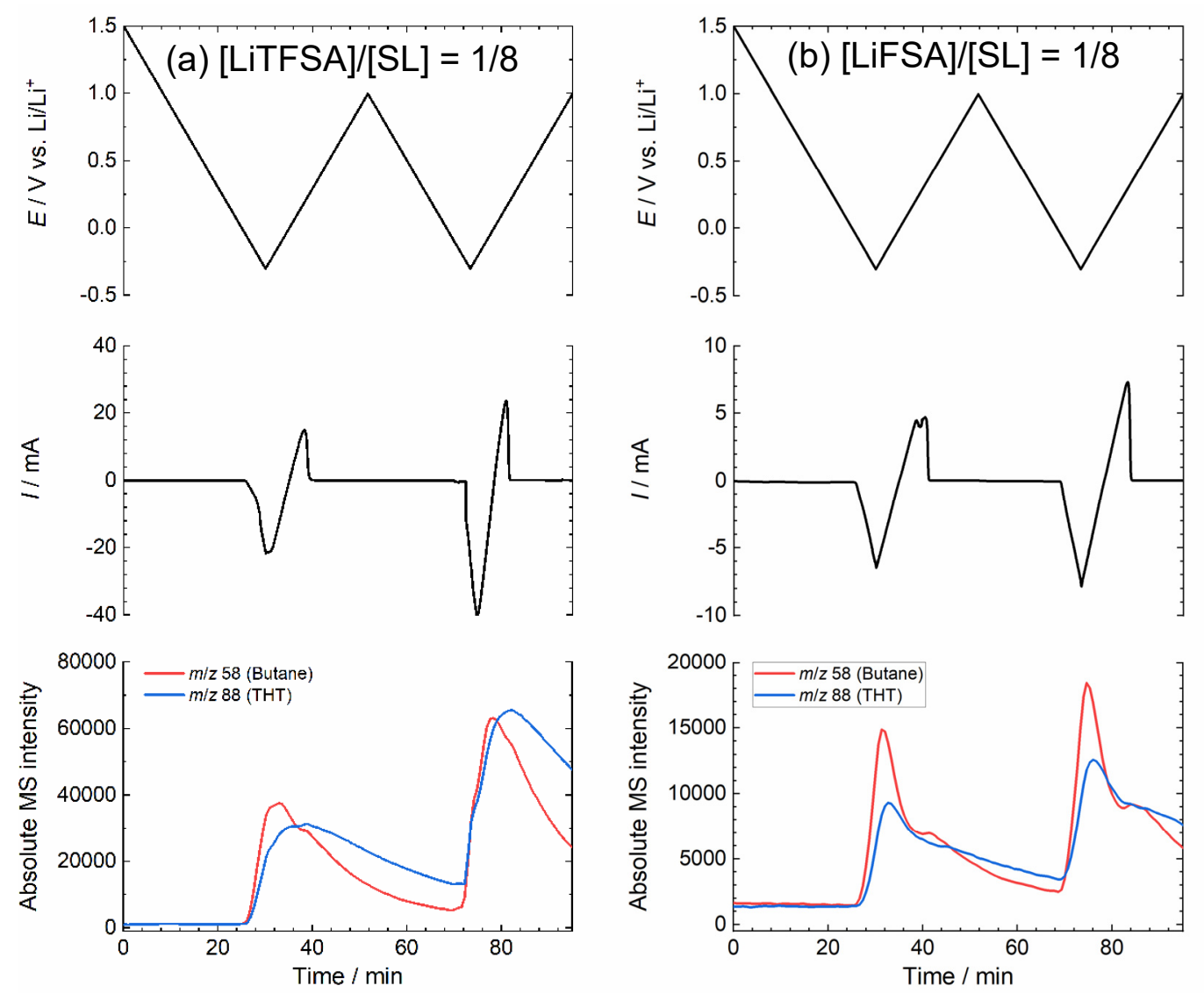

Figure S4. MS intensities of the molecular-ion peaks of butane and THT observed for $\mathrm{Li} / \mathrm{Cu}$ cells with (a) $[\mathrm{LiTFSA}] /[\mathrm{SL}]=1 / 8$ and $(\mathrm{b})[\mathrm{LiFSA}] /[\mathrm{SL}]=1 / 8$ electrolytes during the initial two $\mathrm{CV}$ cycles at a scan rate of $1 \mathrm{mV} \mathrm{s}^{-1}$ at $30^{\circ} \mathrm{C}$.

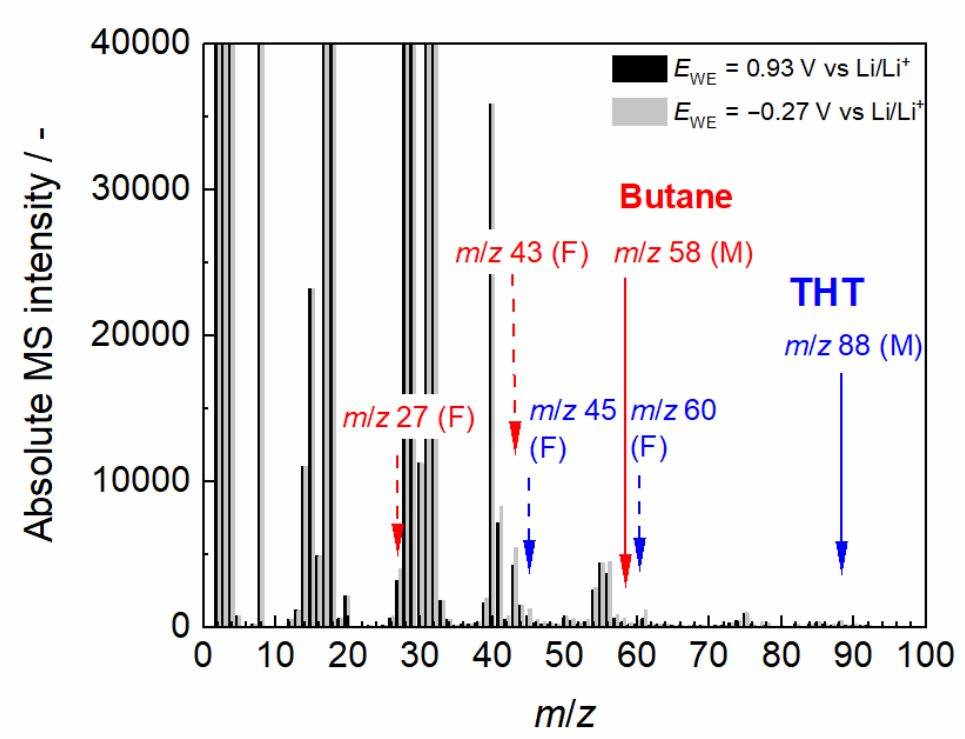

Figure S5. Mass spectra for the $\mathrm{Li} / \mathrm{Cu}$ cell with the $[\mathrm{LiFSA}] /[\mathrm{SL}]=1 / 3$ electrolyte at 0.93 and $-0.27 \mathrm{~V}$ vs. Li, which correspond to before and during the first Li deposition, respectively. 


\section{Electrochemical Impedance Spectroscopy}

Electrochemical impedance measurements were carried out for the symmetric [Li| electrolyte | Li] cells. A disk-shaped Li-metal foil (16 $\mathrm{mm}$ in diameter) and a glass fiber filter (200 $\mu \mathrm{m}$ in thickness, GA-55, Advantec) wetted with an electrolyte $(100 \mu \mathrm{L})$ were encapsulated in a coin-type cell. The electrochemical impedance of the cell was measured in the frequency range of $100 \mathrm{kHz}-100 \mathrm{mHz}$ with an AC signal of $10 \mathrm{mV}$ at $30^{\circ} \mathrm{C}$.

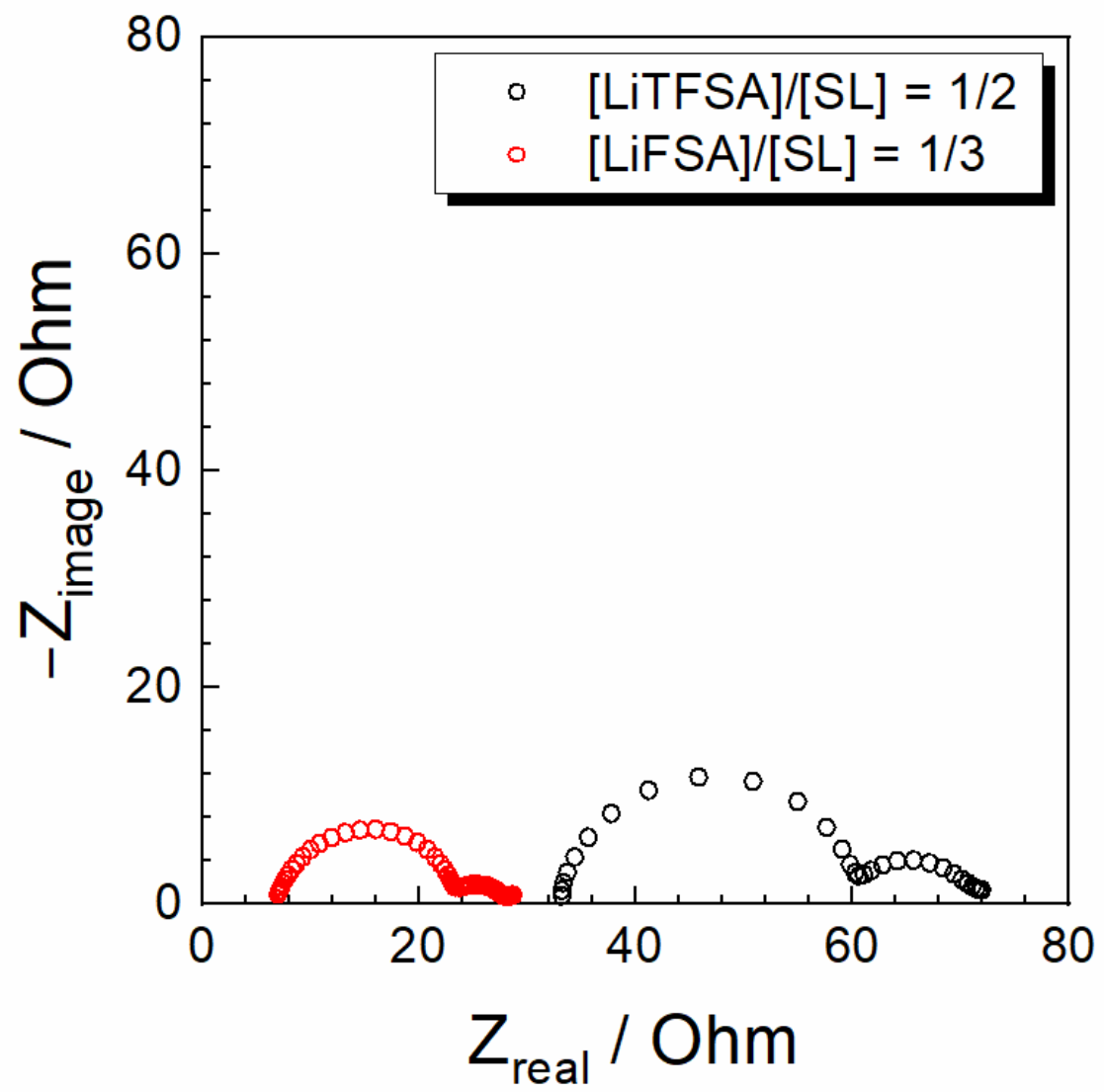

Figure S6. Nyquist plots of the $\mathrm{Li} / \mathrm{Li}$ symmetric cells with the [LiTFSA]/[SL] $=1 / 2$ and $[\mathrm{LiFSA}] /[\mathrm{SL}]$ $=1 / 3$ electrolytes at $30^{\circ} \mathrm{C}$. 


\section{X-ray Photoelectron Spectroscopy}
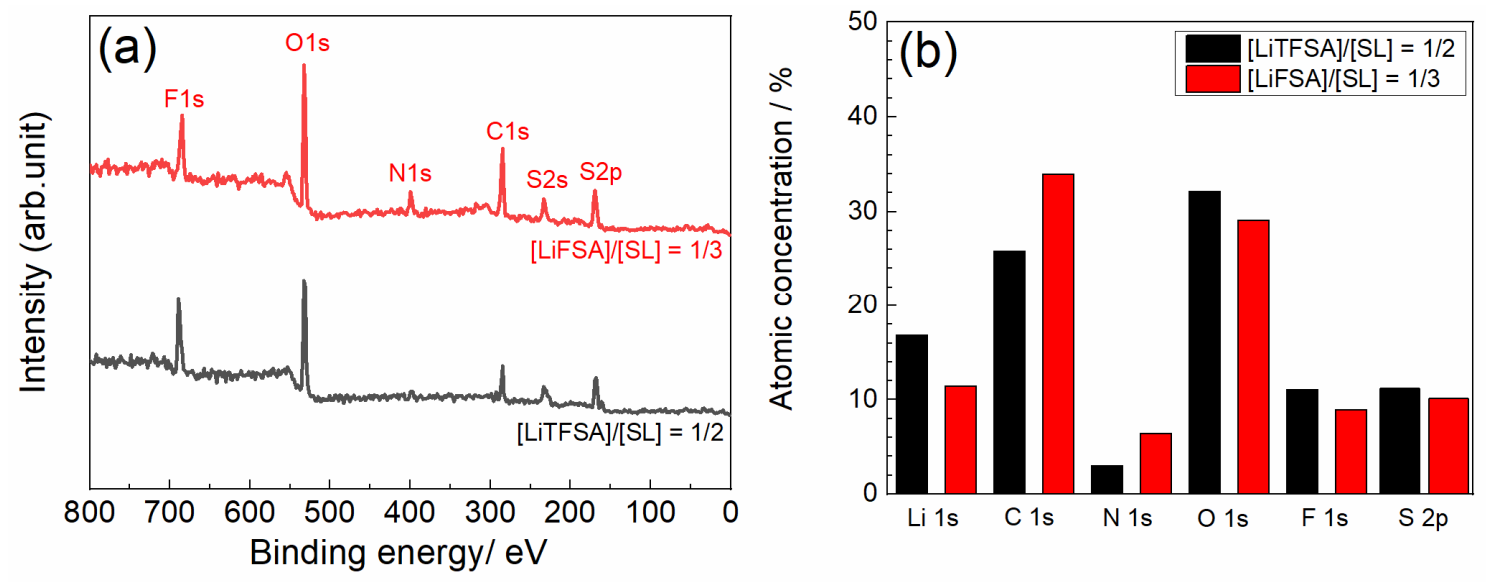

Figure S7. XPS results of the deposited $\mathrm{Li}$ in the $[\mathrm{LiTFSA}] /[\mathrm{SL}]=1 / 2$ and $[\mathrm{LiFSA}] /[\mathrm{SL}]=1 / 3$ electrolytes: (a) XPS survey spectra and (b) surface atomic ratio. 


\section{Cryogenic TEM-EELS Measurements}

Cryogenic TEM-EELS measurements were performed using JEM-ARM200F (JEOL) at $-180{ }^{\circ} \mathrm{C}$. The Li metal was deposited on a $\mathrm{Cu}$ TEM grid at a current of $0.1 \mathrm{~mA}$ for $4 \mathrm{~h}$ in a $[\mathrm{Li} \mid[\mathrm{LiTFSA}] /[\mathrm{SL}]=$ $1 / 2 \mid \mathrm{Cu}$ grid] cell, after which the cell was disassembled in an Ar-filled glovebox. The Cu TEM grid was extracted from the cell, washed with 1,1,2,2-tetrafluoroethyl 2,2,3,3-tetrafluoropropyl ether, and dried under vacuum. The sample was loaded onto a cryo-transfer holder. EELS mapping was carried out using a Digital Micrograph (Gatan).
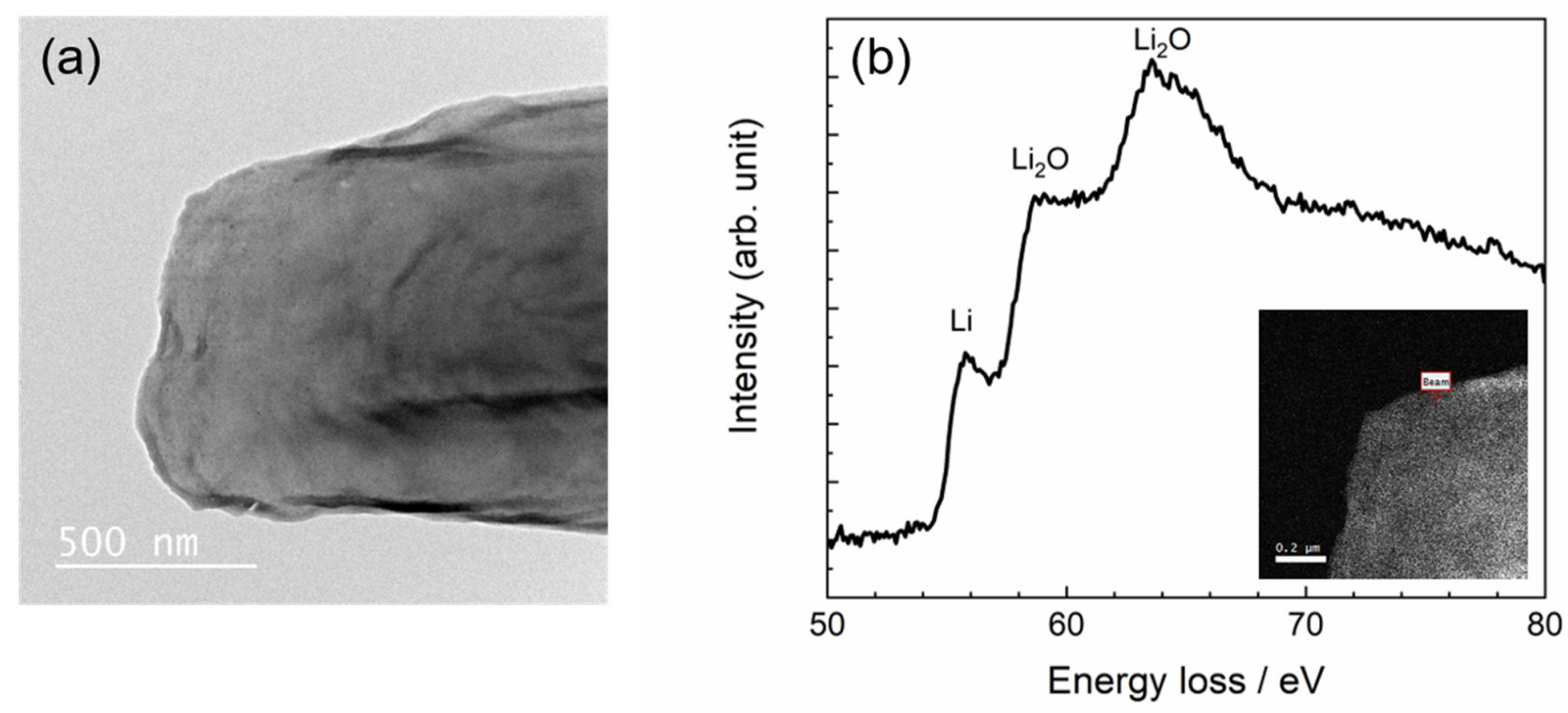

Figure S8. (a) TEM image of the Li metal deposited on the $\mathrm{Cu}$ grid in the [LiTFSA]/[SL] = 1/2 electrolyte. (b) Fine structure of the Li K-edge of the Li deposit. Inset shows an enlarged STEM image of (a). 


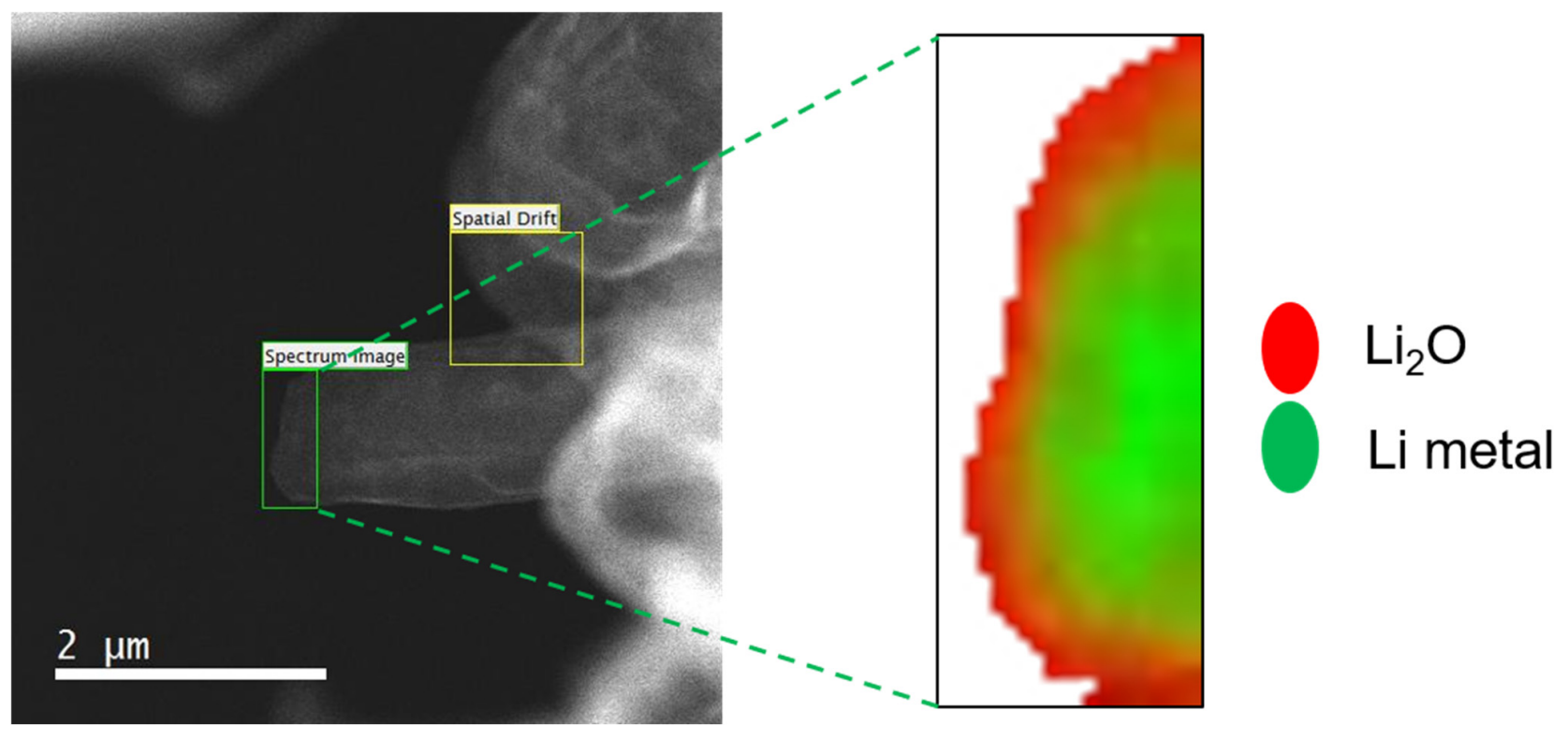

Figure S9. EELS mapping images of $\mathrm{Li}_{2} \mathrm{O}$ (red) and the Li metal (green). 